\title{
Factors Affecting the Teaching-Learning in Nursing Education
}

\author{
Major(Retd)Mrunalini, PhD Dr. Mrs. PAChandekar
}

\begin{abstract}
Most important criteria for effective learning in nursing education is developing Clinical competency by nursing students. Clinical competence mean "is the ability to integrate cognitive, affective and psychomotor skills effectively when delivering nursing care."

The aim of this study was to investigate factors that influence learning by students in nursing education. To achieve this, first studies and theories related to the subjects taught in nursing were reviewed. Some of the most important variables which influence teaching- learning were selected. A descriptive research method was usedin this study. This study was at the Siva Sai Vignan Collegeof nursing, Rajahmundry,Andhra Pradesh. Nursing students were taken as statistical purposive population. Using census and questionnaire Technique, 162 nursing students were studied. Data were analyzed using SPSS version 16. Results showed that there was a positive and significant relationship between independent variables including clinical learning environment, curricular, self efficacy traits, as well as interest, and dependent variable. Women significantly have accessed more clinical competence when compared to male students. There was no significant relationship between variables such as age, previous experience, socio economic data as well as expectancy, and dependent variable.

The Regression analysis results showed that in total, clinical learning environment, gender, self efficacy beliefs and curricular variables explained $31 / 3$ percent of the variance clinical competence as dependent variable. This study showed that the clinical learning environment and curriculum with self-efficacy had the great impact on clinical competency and learning in nursing education. The curriculum and clinical learning environment can have a significant impact on the learning and training of competent nurses.
\end{abstract}

Keyword : Teaching-Learning, Nursing Education, Clinical Competence

\section{INTRODUCTION}

One of the criteria for effective learning in nursing education is clinical competence. Clinical competence is described as the final goal of nursing education. It includes skills of using knowledge and information the student gather, communication and interpersonal skills, problem-solving and technical skills. Nursing faculty are the one responsible for promoting clinical competence. Nursing faculty should satisfy the needs of society and train nurses who have high-level of clinical competence (Reid, 2000). The nursing competence may be defined as the ability to perform nursing duties and to effectively integrate cognitive, emotional and psychomotor skills during nursing cares (EDCaN, 2008). For this study, clinical competence is defined as a psychological construct including cognitive, emotional and psychomotor areas. In fact, this categorization is based on Bloom's taxonomy (Bloom et al., 1956) for education goals. Therefore, if the nursing student can adequately perform skills related to all three areas, they have high-level clinical competence.

At the end of undergraduate period, the nursing students are expected to achieve the maximum level of clinical competence after receiving necessary and adequate theoretical and practical education and training. The researchers suggest that most new baccalaureate nursing graduates have adequate theoretical knowledge but lack competence in the clinical environment (Scheetz, 1989; Tanner, 1990). Questions arise about why this situation exists. Why are recently graduated students unqualified? What factors affect the teaching and learning and what is the role of education in acquiring nursing competence?

Studying review of literature of researches on nursing, education, academic achievement and professional competence, we selected the variables affecting clinical competence.

\section{INPUT VARIABLES}

Radwin (1998) proposed that experience enhanced the recognition of subtle patient characteristics, promoted intuitive insight, facilitated confidence, and allowed consideration of a broader range of information, intervention and outcomes. Studying factors affecting clinical competence for senior nursing students, Klein and Fowles (2007) 
found that work experience related to health is positively correlated to one of sub-scales of competence (leadership sub-scale). In a case study, Lewis (2010) studied educational barriers and factors affecting nursing

Teaching- learning ,described such factors as motivation, a supportive environment for learning, teaching methods, curriculum design, previous academic success and learning abilities as facilitators of learning.

Learning barriers were also similar: unsupportive environment for learning, teaching methods, curriculum design and pace of program, learning abilities and stress. Thus, in this research students' perceptions of the curriculum, including content, teaching methods and assessment, consider as a factor that affects learning and will eventually lead to competence.

Furthermore, clinical experience is the most important component of nursing education (Walker, 2005; Gaberson and Oermann, 2007). Learning environment provides the setting for learning and at the same time, acts as a participant in teaching and learning (Loughlin and Suina, 1982, cited in Jecklin, 1998 ). It can support, impede or limit learning opportunities for students (Reilly and Oermann, 1992). Learning environment has been described as influencing the development of student cognitive, affective and psychomotor skills (Pascarella and Terenzini, 1991; Hart and Rotem, 1994). Some believe that the students' perceptions of their environment are considered by some to have even more influence on student learning than does the actual environment because the perceptions influence the way a student approaches a task and thus ultimately determine the quality of learning outcomes (Cust, 1996, cited in Jecklin, 1998). If the education system is student-centered, it is important to define students' conceptions of the environment and adjust the environment in order to better learning, because it is possible for students to interpret one environment in different ways. Thus, student's perception of clinical learning environment and his/her experiences can affect the nurse's performance. Clinical learning environment including opportunities and challenges of clinical learning and supports and feedback of nursing teachers has been inserted in the research as a factor affecting clinical competence.

\section{Process Variables}

Self-efficacy refers to opinions and beliefs of people about their abilities and eligibilities in controlling their performance and consequents affecting the life. In nursing education, especially clinical education, little studies have been done on nursing students' self-efficacy (Andrew, 1998). Moreover, little researches have distinctly studied the effect of these factors on academic and clinical performance (Opacic, 2003). Harvey and McMurray (1994) have demonstrated that the less self-efficacy students have, the less opportunity to pass academic courses. Bandura (1995) states that self-efficacy is one of personal beliefs that people need it to success and may shows its way of thinking and action. So, it can be stated that professional eligibility is related to self-efficacy. Functional failure is not necessarily stemmed from weak performance, but, less self-efficacy may be a factor of ineffective use of achieved skills (Bandura, 1997). Harvey and McMurray (1994) have stated that self-efficacy affects professional improvement of clinical nurses

In expectancy-value theory, motivation is ordered by this expectancy that the behavior has a special outcome which is valuable (Wigfield, 1997).

Obviously, if it is assumed that an education consequent is unachievable or invaluable, students will be unmotivated (Bandura ,1995, cited from Landry, 2003). Consequents expectation and values are not sufficient to provoke highlevel performance. For example, students may believe that of their hard work, they will be graduated and get a good job (expecting a positive consequent), but they may seriously doubt their capabilities to learn the materials on an exam (low self-efficacy). Self-efficacy and consequent expectation are related, but they are separable in situation, in which outcomes are poorly linked with performance quality (for example, when all students get good scores and they are graduated regardless of performance). Low self-efficacy expectations may prevent a person from attempting to perform a task even if he/she is certain that the performance of that task would lead to desired outcome. Successful performance of a given behavior is the most powerful source of for strong self-efficacy expectations (Hacket \& Webtz, 1981; Bandura, 1997).

Lent's performance model has been tested in relation to what influences ongoing performance and persistence. Social Cognitive Career Theory (SCCT) provides a framework that relates concepts from the existing career theories with the intent to identify and explain the dynamic relationship between variables that affect academic and career interest development, choice and performance (Lent and Brown, 1996; Lent et al., 2002). Primary variables in SCCT including self-efficacy, outcome expectation and goals are derived from Bandura's social cognitive theory. These three variables are considered key to person's career development and reflect the person's agency or self-direction (Lent, 2002). 
The main framework of SCCT includes three models reflecting academic and career development. These three models are as follows: interest development, choice and performance. In the first model, interest development, variables of self-efficacy and outcome expectation directly influence interest choices. People tend to identify with interests that are reinforced by positive self-efficacy and outcome expectation (Lent and Brown, 1996). Also, will develop a disinterest in activities that cause self-efficacy doubt and expectations of negative outcome (Lent and Brown, 2002, cited from Pakieser-reed, 2006). Choice as the second model is more complicated model than interest. Additional variables are incorporated in the model: include person inputs, distal contextual affordances and contextual influences proximal to choice behavior. person Inputs essentially reflect the person's genetic and health factors. Distal contextual affordances include the person's background, family, culture and socioeconomic influences. Both person input and contextual variables affect personal learning experiences. These experiences are the primary source of self-efficacy and outcome expectation (Lent et al., 2002). Comparing the before two models, the third model, performance model, is a rather simple model. The performance is the level of accomplishment and the persistence of behavior in career-related pursuits (Lent et al., 2002,p 277). Having a performance model plays an important role in a career. The key variables in this model are: ability or past performance, self-efficacy, outcome expectation, performance goals and Performance attainment. Ability or past performance reflects person's achievement, aptitude and performance experiences. The ability affects the development and ongoing assessment of self-efficacy and outcome expectation which then affects performance goals and performance attainments. performance attainment loops back to ability and the cycle continues with adaptation based on this new information (Lent et al., 2002).

\section{THEORETICAL FRAMEWORK}

According to three performance models of Lent, variables of self-efficacy belief, outcome expectations and interest as intermediate variables and input variable including individual variables (age, sex and before experiment) and educational variables (content of the curriculum and the perception of the clinical learning environment) have been inserted into the research.

Although there are reliable findings about academic performance of nursing students, there are little data in hand about factors of achieving clinical competence. Doing this research, we can enrich current knowledge in this field in addition to indicate factors affecting clinical competence.

\section{Methodology}

\subsection{Sample and Data Collection Method}

This research is a descriptive study of correlation type. The population includes undergraduate students of all 4 years of nursing students of SSV college of nursng and SSV school of nursing studens were taken who are affiliated to NTR university. Data for this research were collected through census of nursing students of all 4 years of nursing students of SSV college of nursng and SSV school of nursing studens, these two units. A total of 162 questionnaires were collected. To fill the questionnaire, students were asked to accurately identify their achieved skill level in each statement. The confidentiality of answers was insisted on. Each student had 15 minutes for filling the questionnaire. SPSS-16v was used for data analysis.

\section{INSTRUMENTATION}

In the present research, the questionnaire was used to collect data. Instrumentation of this research is divided into some parts. The first part was demographic information questions and questions related to interest and before experience.

$>$ The second part related to clinical competence questionnaire.

$>$ The third part was related to educational factors questionnaire.

$>$ The next part was about self-efficacy beliefs and the last part was related to outcome expectation questionnaire.

In the present research, a self assessment method was used to measure clinical competence. The used questionnaire is made by the researcher through combining, amending and classifying items of some other clinical questionnaires (schwirian, 1978; Scheetz, 1989; Williams, et al., 2008; Vanaki, 2009). questionnaire items divided into three areas of cognitive, affective and psychomotor and ordered based on nursing process. The validity of this questionnaire has been approved by the nursing professors and counselors. 
Educational factors are related to two variables of curriculum and clinical learning environment. Curriculum variable is supported by questions about the relationship between curriculums, teaching methodology, evaluation methods in nursing course and desirable, effective performance of students. In fact, these questions measure students' idea about curriculum including content, relation between theoretical and practical courses, teaching methods and evaluation methods. These questions are researcher-made and were designed adopting some instruments about the relation between performance and education. Statements of clinical learning environment variable are a researcher-made and adopted one. The validity of statements of this questionnaire has been approved by the professors.

The following Table 1 indicates the measures of the study variables used in the study. The reliability of this questionnaire was also indicated by a pre-test and measuring Cronbach's alpha coefficient. Self-efficacy scale and Outcome expectations scale items were adopted from previous studies by Schwarzer \& Jerusalem(1995) and Landry (2003).

Table1. Instrumentation of the study variables

\begin{tabular}{|l|l|l|l|l|}
\hline Study variables & $\begin{array}{l}\text { No.of } \\
\text { items }\end{array}$ & Source of scale & Type of scale & $\begin{array}{l}\text { Cronbach's alpha } \\
\text { coefficient }\end{array}$ \\
\hline Clinical competence & 31 & Researcher maker & 5-points Likert scale & $0 / 94$ \\
\hline Educational factors & 24 & Researcher maker & 5-points Likert scale & $0 / 83$ \\
\hline Self efficacy & 10 & $\begin{array}{l}\text { Schwarzer\& } \\
\text { Jerusalem(1995) }\end{array}$ & 5-points Likert scale & $0 / 88$ \\
\hline Outcome expectation & 16 & Landry(2003) & 5-points Likert scale & $0 / 84$ \\
\hline
\end{tabular}

\section{FINDINGS}

The age spectrum of the population with 162 samples was 20-30 with the mean age of 22.2.

67.3 percent of the sample was female. 21 percent of the sample had before (MPW)experience related to health. The average of clinical competence was 3.44 percent for females and 3.21 percent for males. There is a significant relationship between sex and clinical competence $(\mathrm{t}=2.21, \mathrm{P}<0.05)$. Females achieved significantly more clinical competence than males. However, there is no significant relationship between those who had experience in nursing and practice and those who had no experience in this field.

Study of correlation coefficients (Table 1) shows that student's clinical competence is significantly correlated to curriculum, clinical learning environment, self-efficacy and interest. Among correlation coefficients for predictor variables with clinical competence, clinical learning environment and curriculum variables have the highest correlation coefficients. The least amount was 0.199 related to interest variable. Also, the clinical competence has no significant correlation with age and outcome expectation variables.

Table2. Hypothesis Test

\begin{tabular}{|l|l|l|l|l|l|l|}
\hline variables & Mean & Std.devision & Min score & Max score & r & sig \\
\hline Age & $22 / 25$ & $1 / 28$ & 20 & 30 & $-0 / 052$ & $0 / 51$ \\
\hline curriculum & 3 & $0 / 58$ & $1 / 57$ & $4 / 43$ & $0 / 429$ & $0 / 000^{* *}$ \\
\hline $\begin{array}{l}\text { Clinical learning } \\
\text { environment }\end{array}$ & $3 / 34$ & $0 / 5$ & $2 / 24$ & $4 / 71$ & $0 / 449$ & $0 / 000^{* *}$ \\
\hline Self efficacy & $3 / 7$ & $0 / 6$ & $1 / 5$ & 5 & $0 / 372$ & $0 / 000^{* *}$ \\
\hline $\begin{array}{l}\text { Outcome } \\
\text { expentetion }\end{array}$ & $3 / 2$ & $0 / 65$ & $1 / 46$ & $4 / 85$ & $0 / 089$ & $0 / 26$ \\
\hline Interest & $7 / 23$ & $2 / 37$ & 1 & 10 & $0 / 199$ & $0 / 01^{*}$ \\
\hline $\begin{array}{l}\text { Clinical } \\
\text { competence }\end{array}$ & $3 / 3$ & $0 / 62$ & $1 / 65$ & $4 / 81$ & & \\
\hline
\end{tabular}

$* P<0 / 05$

$* * P<0 / 001$

Table 2 and Figure 2 show direct and indirect effects and all independent and intermediate variables. Variables have been ordered according to their effects on dependent variable. All variable except age, outcome expectation and interest have been entered into the analysis model. Path coefficients indicate that the gender, self-efficacy and 
curriculum variables directly affect the dependent variable without any indirect influence. The clinical learning environment affect both directly and indirectly the dependent variable. The before experience variable affects indirectly the dependent variable. The negative relationship between gender and dependent variable means that females achieved more clinical competence than males. Other variables are directly related to dependent variable.

Table3. Direct, Indirect and Total Effects of Independent Variables on clinical competence

\begin{tabular}{|l|l|l|l|}
\hline variables & Direct effect & Indirect effect & Total Effect \\
\hline $\begin{array}{l}\text { Clinical learning } \\
\text { environment }\end{array}$ & $0 / 309$ & $0 / 087$ & $0 / 396$ \\
\hline Self efficacy & $0 / 200$ & & $0 / 200$ \\
\hline Gender & $-0 / 198$ & & $-0 / 198$ \\
\hline Curriculum & $0 / 19$ & & $0 / 19$ \\
\hline Previous experience & - & $0 / 0346$ & $0 / 0346$ \\
\hline
\end{tabular}

\section{CONCLUSION}

Clinical competence is an important outcome in nursing education. Evaluating clinical eligibility and indicating factors affecting it may be helpful in promoting the quality and effectiveness of nursing education. The present research is to evaluate clinical competence of nursing students and to indicate its effective factors. To do this, the theoretical and empirical frameworks were created and the variables were evaluated using questionnaire. The conceptual framework of this research includes personal, educational and intermediate variables as predictor variable and clinical competence variable as the criterion. Personal variable are age, gender and before experience; educational variables are curriculum and clinical learning environment; intermediate variables are self-efficacy beliefs, outcome expectation and interest.

The results for hypothesis testing of correlation between independent and intermediate variables and clinical competence show that gender, curriculum, clinical learning environment, self-efficacy and interest have significant relationship with dependent variable.

Gender is significantly related to competence. The average score of females was significantly more that males'. Also in the model, gender has direct effect on clinical competence. This result could be due to the fact that females have evaluated their competency higher because of their higher level of accuracy and skill. However, the results should be interpreted with caution for females were twice number of females versus males.

However, research has not mainly found a significant relationship between gender and clinical competence (Klein and Fowels, 2007; Blackman et al., 2009).

There was no significant relationship between age and clinical competence. In Klein and Fowels (2007) research, age was adversely depended on some other sub-scales of competence. Before experience has no significant correlation with clinical competence. This finding was inconsistent with results of Klein and Fowels (2007) research. That's may be due to the less number of sample with before experience versus without before experience. It also may be possible that before experience in a field related to health may not lead to clinical competency. It means that factors and situations after entering nursing education period are more effective in acquiring clinical competence.

On the relationship between educational variable and clinical competence variable, findings show that both variables of curriculum and clinical learning environment are significantly correlated. Correlation coefficient of curriculum and clinical competence is 0.429 which seems to be high.

It means that respondents who have positive opinion about the curriculum, acquired higher clinical competence. The curriculum variable has considered students' idea about content, teaching and evaluation methods, and the relation of theoretical and practical course. This finding suggests that the curriculum and teaching-learning processes directly affect clinical competence. In Lewis (2010), students had considered curriculum and teaching methods as educational barrier affecting nursing education.

The correlation coefficient of clinical learning environment and clinical competence was 0.449. It shows that students who consider clinical environment as a suitable place for learning, evaluated their clinical competence in higher level. It means that clinical environment atmosphere, behavior of nurses and staffs of hospital, equipments and facilities needed for education and treatment, clinical teaching methods, all affect acquiring clinical competence. 
Among intermediate variables, self-efficacy and interest had a positive and significant relationship with clinical competence. Students with high self-efficacy had obtained higher clinical competence. This finding is consistent with Opacic's research (2003). However, the Opacic (2003) research has not directly addressed the clinical competence and the relationship between self-efficacy and clinical performance was significant. This result agrees with the idea of Harvey and McMurray (1994) according which self-efficacy can affect career improvement.

The result shows that there is a significant relationship between interest and clinical competence. The correlation coefficient of interest and competence is 0.199 which shows a rather weak relation between these two variables. Although no research has been done in this regard, such result was predictable; because career, motivation and interest are a strong stimulus for performance according to social-cognitive theory of career.

\section{REFERENCES}

[1] Andrew, S.W.(1998). Self-efficacy as a predictor of academic performance in science. Journal of Advanced Nursing, 27, 596-603

[2] Bandura, A.(1997).Self-efficacy:The exercise of control. New York: freeman.

[3] Baramee, J ., \& Blegen, M. A .(2003). New graduate perception of clinical competence: testing a causal model. International Journal of Nursing studies, 40(2003), 389-399

[4] Blackman, I ., Hall ,M., \& Darmawan, I , J. (2007). Undergraduate nurse variables that predict academic achievement and clinical competence in nursing. Journal of International Education, 8(2), 222-236

[5] EdCaN. (2008). Competency assessment in nursing: A summary of literature published since 2000. Retrieved from www.edcan.org/pdf/EdCancompetenciesliteraturereviewFINAL.pdf

[6] Gaberson, K. B., \& Oermann, M, H. (2007). Clinical teaching strategies in nursing (2nd ed.). New York: Springer Publishing.

[7] Hackett, G., \& Betz, N. E. (1981). Aself-efficacy approach to the career development of women. Journal of Vocational Behavior, 18, 326-339.

[8] Hart, G., Rotem, A.( 1994). The best and the worst: students'experiences of clinical education. Australian Journal of Advanced Nursing, 11 (3), 26-33.

[9] Harvey, V., \& McMurray, N. (1994). Self-efficacy: a means of identifying problems in nursing education and career progress. International Journal of Nursing Studies,

[10] $31,471-85$

[11] Klein ,C. J \& Fowles, E. (2007). An investigation of nursing competence and the competency outcomes performance assessment curricular approach: senior student 's self-reported perceptions. Journal of Professional Nursing, 25(2), 109121

[12] Landry, C.C.(2003). Self-efficacy, motivation, and outcome expectation correlates of college students intention certainty. Unpublished Doctoral Dissertation, Louisiana State University, Louisiana.

[13] Lent, R.w., \& Brown, S.D. (1996). Social cognitive approach to career development:An overview. The Career Development Quarterly, 44, 310-321.

[14] Lent, R. W., Brown, S. D., \& Hackett, G. (2002). Sccial cognitive career theory. In D. Brown(ED), Career choice and development(4th ed., pp.255-311).San Francisco: Jossey-Bass.

[15] Lewis, E. J. (2010).How accelerated nursing student learn: a comparative case study of the facilitators, barriers, learning srtrategies, challenges and obstacles of students in an accelerated nursing program. . PhD Dissertation, the university of Wisconsin-Milwaukee.

[16] Opacic, D. A. (2003). The relationship between self-efficacy and student physician assistant clinical performance. Journal of Allied Health, 32, 66-158

[17] Pascarella, E. T., \& Terenzini, P.T. ( 1991). How College Affects Students. Jossey-Bass, San Francisco

[18] Pakieser-Reed, K. (2006).Nursing practice self-efficacy and nursing practice outcome expectations in baccalalaureate nursing students. PhD Dissertation, the university of columbia.

[19] Radwin, L. E. (1998). Empirical generated attributes of experience in nursing. Journal of Advanced Nursing, 27, 590-595.

[20] Reid ,F.(2000). Baccalaureate education and professional practice. Nurse Outlook, 15(3),50- 59

[21] Reilly, D. E. \& Oerman, M. H. (1992). Clinical teaching in nursing education. NewYork:National League for Nursing.

[22] Sand-Jecklin, k. (1998). Student evaluation of clinical education environment(SECEE): instrument development and valdation. Unpublished Doctoral Dissertation, West Virginia University, West Virginia

[23] Scheetz, L. J. (1989). Baccalaureate nursing student preceptorship programs and the development of clinical competence. Journal of Nursing Education, 28, 29-35. 
American Research Journal of Nursing, Volume 1, Issue 4, 2015

ISSN 2379-2922

[24] Schwarzer, R., \& Jerusalem, M. (1995). Generalized Self-Efficacy scale. In J. Weinman, S. Wright, \& M. Johnston, Measures in health psychology: A user's portfolio. Causal and control beliefs (pp. 35-37). Windsor, UK: NFER-NELSON.

[25] Schwirian, P. M. (1978). Evaluating the performance of nurses. Nursing Research, 27, 347-351.

[26] Tanner, C. A. (1990). Reflection on the curriculum revolution: the practice mandate. Journal of Nursing Education, 29, 295-299.

[27] Vanaki, Z. \& Memarian, R.(2009). Professional ethics: beyond the clinical competence. Journal of professional nursing, 25(5), 285-291

[28] Walker, K. (2005). Postmodern pedagogy and the nursing curriculum: Collaborating for excellence. Collegian, 12, 36-40.

[29] Wigfield, A. (1997).Reading motivation: A domain- specific approach to motivation. Educational Psychologist, 32,59-68

[30] Williams, P.R., Walker, J.T, Martin, T, Northington, L, Waltman, P, Beachman, T, Grant, L. (2008). Comparing clinical competencies between nursing students with degrees and traditional students. Issues in Educational Research, 18(1) 